\title{
Guidelines for evaluating the environmental performance of Product/Service-Systems through life cycle assessment
}

\author{
Kjær, Louise Laumann; Pigosso, Daniela C. A. ; McAloone, Tim C.; Birkved, Morten
}

Published in:

Journal of Cleaner Production

Link to article, DOI:

10.1016/j.jclepro.2018.04.108

Publication date:

2018

Document Version

Peer reviewed version

Link back to DTU Orbit

Citation (APA):

Kjær, L. L., Pigosso, D. C. A., McAloone, T. C., \& Birkved, M. (2018). Guidelines for evaluating the environmental performance of Product/Service-Systems through life cycle assessment. Journal of Cleaner Production, 190, 666-678. https://doi.org/10.1016/j.jclepro.2018.04.108

\section{General rights}

Copyright and moral rights for the publications made accessible in the public portal are retained by the authors and/or other copyright owners and it is a condition of accessing publications that users recognise and abide by the legal requirements associated with these rights.

- Users may download and print one copy of any publication from the public portal for the purpose of private study or research.

- You may not further distribute the material or use it for any profit-making activity or commercial gain

- You may freely distribute the URL identifying the publication in the public portal 


\section{Accepted Manuscript}

Guidelines for evaluating the environmental performance of Product/ServiceSystems through Life Cycle Assessment

Louise Laumann Kjaer, Daniela C.A. Pigosso, Tim C. McAloone, Morten Birkved

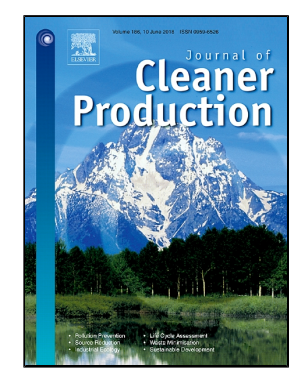

PII:

S0959-6526(18)31135-1

DOI:

10.1016/j.jclepro.2018.04.108

Reference:

JCLP 12689

To appear in:

Journal of Cleaner Production

Received Date:

12 December 2017

Revised Date:

10 April 2018

Accepted Date:

11 April 2018

Please cite this article as: Louise Laumann Kjaer, Daniela C.A. Pigosso, Tim C. McAloone, Morten Birkved, Guidelines for evaluating the environmental performance of Product/Service-Systems through Life Cycle Assessment, Journal of Cleaner Production (2018), doi: 10.1016/j.jclepro. 2018.04.108

This is a PDF file of an unedited manuscript that has been accepted for publication. As a service to our customers we are providing this early version of the manuscript. The manuscript will undergo copyediting, typesetting, and review of the resulting proof before it is published in its final form. Please note that during the production process errors may be discovered which could affect the content, and all legal disclaimers that apply to the journal pertain. 
Title: Guidelines for evaluating the environmental performance of Product/Service-Systems through Life Cycle Assessment

Word count: 9947 (9350 without abstract and references)

Authors: Louise Laumann Kjaer ${ }^{1}{ }^{*}$, Daniela C. A. Pigosso ${ }^{1}$, Tim C. McAloone ${ }^{1}$, Morten Birkved ${ }^{2}$

1 Technical University of Denmark, Department of Mechanical Engineering, 2800 Kgs. Lyngby, Denmark. Emails: $\underline{1 k j @ m e k . d t u . d k}, \underline{\text { danpi@mek.dtu.dk, tmca@dtu.dk }}$

2 Technical University of Denmark, Department of Management Engineering, 2800 Kgs. Lyngby, Denmark. E-mail: birk@dtu.dk

Manuscript correspondence:

*Corresponding author:

Louise Laumann Kjaer

Address: Nils Koppels Allé, Building 404, 2800 Kgs. Lyngby

Denmark

Email: Ilkj@mek.dtu.dk

Telephone: +45 26172687 


\begin{abstract}
Product/Service-Systems (PSS) such as integrated solutions, performance-based contracts or sharing systems are often proposed as means to enable improved environmental sustainability. However, PSS are not necessarily environmentally benign compared to conventional systems. Quantitative environmental performance evaluations of PSS are hence needed. Life cycle assessment (LCA) is a commonly used method for environmental performance evaluation. However, applying LCA in the context of PSS requires specific considerations, which are not sufficiently addressed by current LCA guidelines. In this article, we propose a set of guidelines consisting of six steps, which elaborates the LCA process with respect to the specific consideration for PSS assessment. The guidelines were developed based on identified challenges for the application of LCA on PSS, a review of existing LCAs on PSS case studies, expert consultations, case study applications, and structured user feedback. The use of the guidelines is demonstrated on three exemplifying cases, covering three different scopes for PSS evaluation. By applying the guidelines, the risk of biased results, predictable rebound effects and significant cut-of errors should be reduced. Future work includes evaluating the guidelines through full-scale case applications and further development of dynamic and prospective modelling approaches for assessing systemic consequences and rebound effects.
\end{abstract}

Key words: Product/service-systems, life cycle assessment, environmental evaluation, rebound effects, environmental impact, circular economy 


\section{INTRODUCTION}

The Product/Service-Systems (PSS) concept originates from a sustainability perspective. One of the most cited definitions of PSS (Haase et al., 2017) is that of Mont (2002) who defines PSS as: A system of products, services, supporting networks and infrastructure that is designed to be: competitive, satisfy customer needs and have a lower environmental impact than traditional business models. Since then, the PSS field has grown and environmental aspects are no longer the most influential aspects of the research stream (Annarelli et al., 2016). Nevertheless, PSS continues to be acknowledged as a potential enabler for transitioning towards a more sustainable society. Bocken et al. (2014) explain how PSS plays an important role in the sustainable business model archetype 'deliver functionality, rather than ownership', and PSS are often mentioned as a means to enable a transition from a linear to a circular economy (Kjaer et al., 2018). PSS range from product-oriented (e.g. after-sale services such as maintenance and consultancy) to resultoriented (e.g. the customer pays for an overall result delivered) with use-oriented (e.g. product renting, sharing or pooling) categorised in between (Tukker and Tischner, 2006). While the potential for PSS (and especially result-oriented PSS) to lead to improved environmental performance is often conveyed (Tukker and Tischner, 2006), it is also recognised that a transition towards PSS needs to be combined with e.g. efficiency, value in waste (Bocken et al., 2014) or 'clean' product implementation (Scheepens et al., 2016), in order to realise this potential. Furthermore, even if a net resource or impact reduction is established, burden shifting and rebound effects (when actual impact savings are less than expected because of behavioural or systemic responses) need to be mitigated (Kjaer et al., 2018).

As such, evaluating the environmental performance of PSS is relevant for determining under which circumstances PSS lead to environmental improvements, in order to support decision-making during PSS design and implementation or when optimising existing PSS.

Life cycle assessment (LCA) is a well-established and standardised method for environmental evaluations of products. However, using LCA in the context of PSS is challenging. Current LCA guidelines are inherently product-focused and do not deal explicitly with the characteristics of PSS. Furthermore, relatively few case studies of using LCA on PSS exist in the scientific literature (Kjaer et al., 2016). Three main challenges identified in Kjaer et al. (2016) are:

(i) Identifying and defining the reference system: How to identify and describe the relevant reference systems to which the PSS in question are to be compared? Three scopes for PSS assessments were defined: (1) PSS optimisation (reference system is the existing PSS); (2) PSS comparison (the reference system is one or more pre-defined comparable alternatives, often the traditional business model); (3) PSS consequences (reference system is defined as the baseline situation without the PSS).

(ii) Defining the functional unit: How to ensure functional equivalence upon definition of the functional unit (FU)? If relevant sub-functions are not included, an imbalance in terms of functional outcome and quality occurs. Furthermore, discrepancies in user perceived value may result in rebound effects.

(iii) Setting system boundaries: How to ensure a sufficient level of completeness in system boundaries (which includes products and services in the background system) to avoid truncation errors, leaving out potentially important contributing processes? 
In this article, we propose guidelines for evaluating the environmental performance of PSS applying the LCA methodology. We explicitly address the three challenges by elaborating the goal and scope definition phase of the LCA in order to ensure: (i) a proper exploration of the reference system; (ii) a comparability assessment of the systems to be analysed, to support the functional unit definition; and (iii) a sufficient inclusion of relevant processes in the system boundary decision.

\section{RESEARCH METHOD}

The development of the guidelines followed the hypothetico-deductive approach (Gill and Johnson, 2010), based on a number of iterations (cycles) for the formulation and test of the theory. A mix of research methods (e.g. structured expert interview, user feedback and case studies) were applied (Figure 1).

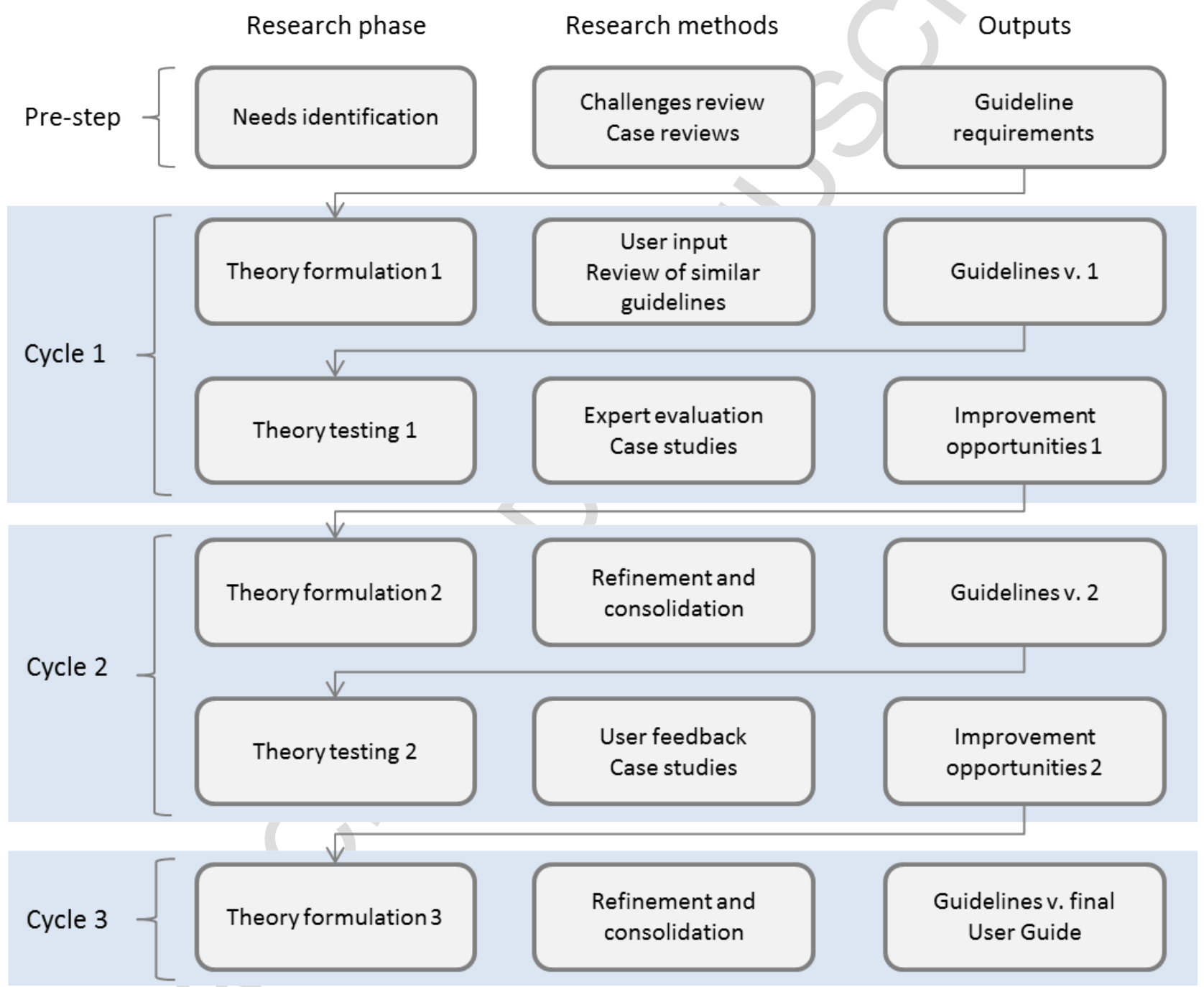

FIGURE 1: THE GUIDELINE DEVELOPMENT PROCESS FOLLOWING THE HYPOTHETICO-DEDUCTIVE APPROACH

Pre-step:

In the pre-step, guideline requirements were formulated (see section 3 ).

Cycle 1: 
The Danish environmental think-thank CONCITO was identified as a potential user of the guidelines and was asked to provide input to the requirements through interviews. Simultaneously, other similar guidelines were reviewed, ranging from consolidated LCA guidelines (e.g. ISO (2006); European Commission (2010); Weidema et al. (2009)) to more novel guidelines for specific application contexts (e.g. CONCITO (2012); ICCA \& WBCSD (2013); Global e-Sustainability Initiative (2010)). Based on these inputs, the first version of the guidelines was developed.

The guidelines were sent to five experts within the field, who were asked to review them. They provided a mixture of written and oral feedback through personal semi-structured interviews. Two hypothetical cases, a bike sharing system (case 1) and a shared lawnmower PSS (case 2), were formulated in order to exemplify the guidelines' application. These case studies were supplemented with inputs from a case study of a hull cleaning service (case 3) documented in Pagoropoulos et al. (2017). Inputs from the experts and the case studies resulted in consolidated improvement opportunities.

Cycle 2:

Through refinement and consolidation, a revised version (v.2) of the guidelines was developed. The guidelines were then tested in connection to another case study: a merino wool garments PSS for the British military, documented in Bech et al. (submitted). In order to obtain additional user feedback and further validate the guidelines, a two-day course for researchers, PhD students and industry professionals working with PSS and LCA was developed. The course was arranged as a structured experiment where the delegates went through the proposed steps using the aforementioned case 1, 2 and 3 . The course ended with a survey in which the delegates provided detailed feedback to each step of the guidelines, resulting in a new set of improvement opportunities.

Cycle 3:

The guidelines were revised once more into the final version as presented in this article, and which also make up the backbone of a pedagogical User Guide, targeting practitioners working with PSS evaluation (Kjaer et al., 2017).

\section{GUIDELINE REQUIREMENTS}

The guideline requirements were identified based on LCA challenges for PSS (as described in the introduction) and on case reviews. Twenty cases dealing with the "environmental quantification of PSS" were identified by means of an update of the systematic literature review, carried out by Kjaer et al. (2016) (see Table 1). The goal was to describe existing approaches for environmental evaluations of PSS, based on the study timing (i.e. pre or post implementation), the study scope and the method applied. This would influence the guidelines, which should not only deal with the aforementioned challenges, but also encompass existing approaches. 
TABLE 1: CASES OF QUANTITATIVE ASSESSMENTS OF PSS

\begin{tabular}{|c|c|c|c|c|c|c|c|}
\hline \multirow[t]{2}{*}{ Case } & \multicolumn{2}{|c|}{ Study timing } & \multicolumn{3}{|c|}{ Study scope } & \multirow{2}{*}{$\begin{array}{l}\text { Assessment } \\
\text { method applied } \\
\text { *as stated in the } \\
\text { reference }\end{array}$} & \multirow[t]{2}{*}{ References } \\
\hline & 'Pre' & 'post' & $\begin{array}{l}\text { PSS } \\
\text { optimi- } \\
\text { sation }\end{array}$ & $\begin{array}{l}\text { PSS } \\
\text { compa- } \\
\text { rison }\end{array}$ & $\begin{array}{l}\text { PSS } \\
\text { conse- } \\
\text { quences }\end{array}$ & & \\
\hline $\begin{array}{l}\text { Optimised waste glass } \\
\text { collection }\end{array}$ & $\mathrm{X}$ & & $\mathrm{x}$ & $(X)$ & & $\mathrm{LCA}^{*}$ & $\begin{array}{l}\text { (Lelah et al., 2011) } \\
\text { (primary) } \\
\text { (Bonvoisin et al., 2014) } \\
\text { (supplementing) }\end{array}$ \\
\hline $\begin{array}{l}\text { Bicycle sharing in the } \\
\text { city of Lyon }\end{array}$ & & $X$ & $X$ & $\mathrm{x}$ & & LCA $^{*}$ & (Amaya et al., 2014) \\
\hline $\begin{array}{l}\text { Paper mill } \\
\text { reconditioning }\end{array}$ & & $\mathrm{X}$ & & $x$ & & $\mathrm{LCA}^{*}$ & (Lindahl et al., 2014) \\
\hline $\begin{array}{l}\text { Clean and dry building } \\
\text { exterior }\end{array}$ & & $X$ & & $X$ & & LCA $^{*}$ & (Lindahl et al., 2014) \\
\hline $\begin{array}{l}\text { Leasing of a soil } \\
\text { compactor }\end{array}$ & & $X$ & & $\mathrm{X}$ & & $\mathrm{LCA}^{*}$ & (Lindahl et al., 2014) \\
\hline Clothes washing & $\mathrm{X}$ & & & $\mathrm{X}$ & & LCA & (Haapala et al., 2008) \\
\hline 'Conditioned air' service & $x$ & & & $x$ & & 'Streamlined LCA'* & $\begin{array}{l}\text { (Bennett and Graedel, } \\
\text { 2000) }\end{array}$ \\
\hline $\begin{array}{l}\text { Free-floating car- } \\
\text { sharing system } \\
\text { (car2go in Ulm) }\end{array}$ & $X$ & $X$ & & & $X$ & $\begin{array}{l}\text { Surveys and } \\
\text { 'parameterised } \\
\text { effect analysis' }\end{array}$ & $\begin{array}{l}\text { (Firnkorn et al., 2011) (pre) } \\
\text { (Firnkorn and Müller, } \\
\text { 2012)(post) }\end{array}$ \\
\hline $\begin{array}{l}\text { Household waste } \\
\text { prevention on new } \\
\text { housing developments } \\
\text { in the UK }\end{array}$ & $X$ & & & & $x$ & $\begin{array}{l}\text { Waste prevention } \\
\text { assessment* } \\
\text { (Mass stock } \\
\text { analysis) }\end{array}$ & (Gottberg et al., 2010) \\
\hline $\begin{array}{l}\text { Remanufacturing at Fuji } \\
\text { Xerox }\end{array}$ & & $\mathrm{X}$ & & $X$ & 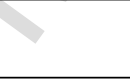 & 'First level' LCA* & (Kerr and Ryan, 2001) \\
\hline $\begin{array}{l}\text { Re-use of temporary } \\
\text { buildings }\end{array}$ & & $X$ & & $X$ & & LCA* $^{*}$ & (Dreijer et al., 2013) \\
\hline $\begin{array}{l}\text { Shared household tools } \\
\text { (drills and lawnmowers) }\end{array}$ & $X$ & & & $x$ & & Simplified LCA & (Mont, 2004) \\
\hline $\begin{array}{l}\text { Environmental sensor } \\
\text { applications }\end{array}$ & & $x$ & $X$ & & & LCA $^{*}$ & (Salazar et al., 2015) \\
\hline $\begin{array}{l}\text { Business models for } \\
\text { transport by car in } \\
\text { Swedish small towns }\end{array}$ & $x$ & & & $x$ & & LCA $^{*}$ & (Nurhadi et al., 2017) \\
\hline $\begin{array}{l}\text { Pallet management } \\
\text { strategies }\end{array}$ & $x$ & & & $x$ & & $\mathrm{LCA}^{*}$ & (Carrano et al., 2015) \\
\hline $\begin{array}{l}\text { Servicizing the farming- } \\
\text { livestock sector }\end{array}$ & & $x$ & & $x$ & & 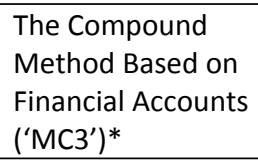 & (Pereira et al., 2016) \\
\hline $\begin{array}{l}\text { Water purifiers for } \\
\text { home use }\end{array}$ & & $X$ & & $X$ & & $\mathrm{LCA}^{*}$ & (Chun and Lee, 2017) \\
\hline $\begin{array}{l}\text { Hull cleaning service of } \\
\text { merchant vessels }\end{array}$ & 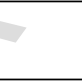 & $X$ & $X$ & & & LCA $^{*}$ & (Pagoropoulos et al., 2017) \\
\hline $\begin{array}{l}\text { Photocopier in a rental } \\
\text { service with } \\
\text { reconditioning }\end{array}$ & & $X$ & & $x$ & & LCA* $^{*}$ & (Khumboon et al., 2009) \\
\hline $\begin{array}{l}\text { Making water tourism } \\
\text { more sustainable }\end{array}$ & $X$ & & $X$ & & & $\begin{array}{l}\text { Eco-costs Value } \\
\text { Ratio (EVR) } \\
\text { model* (LCA- } \\
\text { based) }\end{array}$ & (Scheepens et al., 2016) \\
\hline
\end{tabular}


The review shows that studies conducted pre implementation (ex-ante) and post implementation (ex-post) seem equally important for PSS (even distribution). One case is documented both pre and post implementation (Firnkorn et al., (2011); Firnkorn and Müller (2012)). PSS comparisons and/or PSS optimisations are the most applied scopes, which shows a limited focus on the actual system changes caused by PSS, which again supports that increased focus on the reference system is important. Lastly, in most studies, LCA is stated as the applied assessment method; however some also apply simplified methods (e.g. 'streamlined LCA', 'First level' LCA or 'waste prevention assessment') or adapted methods based on the LCA methodology (e.g. 'parameterised effect analysis', 'Eco-costs Value Ratio (EVR) model', the 'MC3' method).

Together with the identified challenges, the case analyses provided input to the guidelines requirements, as summarised in Table 2.

TABLE 2: GUIDELINES REQUIREMENTS BASED ON KEY FINDINGS FROM LITERATURE REVIEW

\begin{tabular}{|c|c|c|}
\hline Requirement \# & Key findings from literature review & Guideline requirements \\
\hline $\begin{array}{l}\text { \#1 Focus on study } \\
\text { scoping }\end{array}$ & $\begin{array}{l}\text { The identified challenges are } \\
\text { connected to the goal and scope } \\
\text { definition phase of an LCA. }\end{array}$ & $\begin{array}{l}\text { \#1 Guidelines should follow the phases of an LCA, } \\
\text { with specific focus on supporting the goal and scope } \\
\text { phase. }\end{array}$ \\
\hline $\begin{array}{l}\text { \#2 Support } \\
\text { reference system } \\
\text { definition }\end{array}$ & $\begin{array}{l}\text { Challenge \#1: Define the reference } \\
\text { system }\end{array}$ & $\begin{array}{l}\text { \#2 Guidelines should support an exploration of the } \\
\text { reference system to identify relevant substitutions. }\end{array}$ \\
\hline $\begin{array}{l}\text { \#3 Support } \\
\text { functional } \\
\text { equivalence }\end{array}$ & $\begin{array}{l}\text { Challenge \#2: Establish functional } \\
\text { equivalence between the compared } \\
\text { systems in the FU definition. }\end{array}$ & $\begin{array}{l}\text { \#3 The guidelines should support the FU definition, } \\
\text { which should be accompanied by a comparability } \\
\text { assessment, which ensure that: } \\
\text { - All relevant sub-functions are included } \\
\text { - Differences in user perceived value outcome } \\
\text { are assessed (to identify rebound effects) }\end{array}$ \\
\hline $\begin{array}{l}\text { \#4 Support system } \\
\text { boundary definition }\end{array}$ & $\begin{array}{l}\text { Challenge \#3: Ensure a sufficient level } \\
\text { of completeness in system boundary } \\
\text { selection. }\end{array}$ & $\begin{array}{l}\text { \#4 The guidelines should support the identification of } \\
\text { relevant contributing flows and include 'hidden' } \\
\text { processes (e.g. from services, infrastructure) in the } \\
\text { background system. }\end{array}$ \\
\hline $\begin{array}{l}\text { \#5 Support different } \\
\text { approaches }\end{array}$ & $\begin{array}{l}\text { PSS are assessed both post and pre } \\
\text { implementation and methods range } \\
\text { from 'full LCA' to simplified/adapted } \\
\text { versions of LCA. }\end{array}$ & $\begin{array}{l}\text { \#5 The guidelines should support both 'pre' and 'post' } \\
\text { assessment and allow for both a 'full LCA' approach } \\
\text { and more simplified approaches, i.e. a 'screening level } \\
\text { LCA' based on aggregated data. }\end{array}$ \\
\hline $\begin{array}{l}\text { \#6 Focus on } \\
\text { scenario-approach } \\
\text { and qualitative } \\
\text { learnings }\end{array}$ & $\begin{array}{l}\text { LCA studies on PSS are subject to } \\
\text { uncertainty and results usually } \\
\text { dependent on assumption about user } \\
\text { behaviour. }\end{array}$ & $\begin{array}{l}\text { \#6 The guidelines should support a scenario-based } \\
\text { approach and focus should be on the learnings during } \\
\text { the evaluation process, not only the quantified } \\
\text { results. }\end{array}$ \\
\hline
\end{tabular}

\section{Presentation of Guidelines}

The guidelines aim to support organisations, consultants and company employees, who are to perform an environmental evaluation of PSS. Three competence profiles are needed:

- Strategic decision-maker: formulation of desired learnings and results interpretation.

- PSS designer: analysing and defining the PSS solution under study.

- LCA practitioner: performing the quantitative part of the study. 
The developed guidelines consist of six steps and a number of sub-steps (Figure 2). The first four steps support the goal and scope definition phase of an LCA. Step 5 supports inventory analysis and impact assessment and Step 6 supports the Interpretation phase. Similarly to an LCA study, the study process will be iterative in nature.

Steps

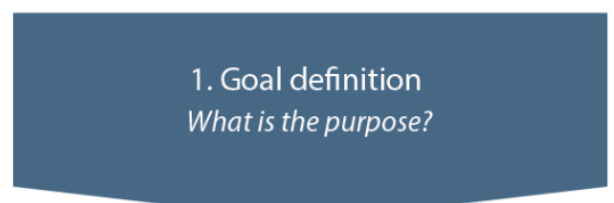

2. PSS and reference system

exploration

What to compare?

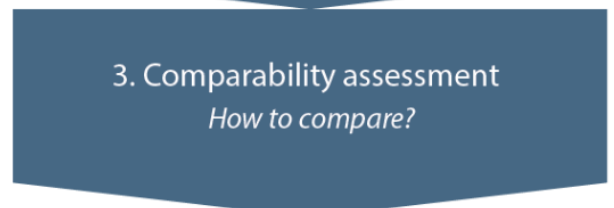

4. Process mapping

What to quantify?

5. Quantification

How to quantify?

\section{Interpretation and \\ recommendations \\ What to conclude?}

Sub-steps

1.1 Study purpose and application

1.2 Study complexity

1.3 Time and resources

2.1 Scope and reference system

2.2 PSS support and substitutions

2.3 PSS potential

2.4 Definition: Systems to be analysed

3.1 System functionality and functional unit

3.2 System subdivision ("How")

3.3 Utility, value and rebound effects ("How well")

4.1 Flowchart

4.2 System boundaries

4.3 Impact categories

5.1 Data gathering

5.2 Calculations

6.1 Result evaluation

6.2 Result communication

6.3 Recommendations (optional)
LCA phases
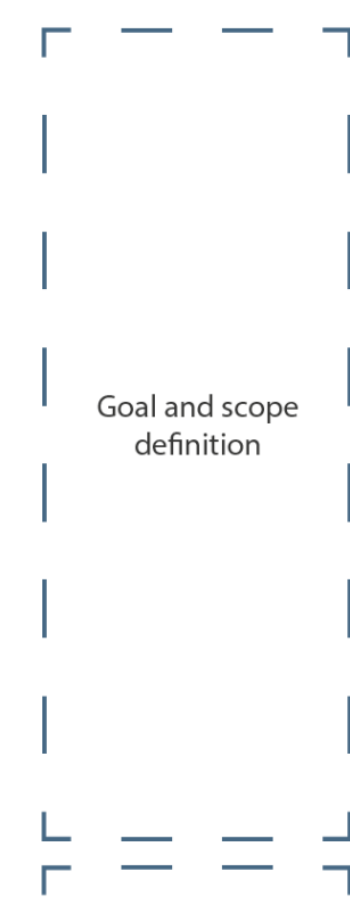

Inventory analysis Impact assessment

ᄃ $\square-\square$

Interpretation

FIGURE 2: OVERVIEW OF STEPS AND SUB-STEPS AND HOW THEY LINK TO THE PHASES OF AN LCA PROCESS

\subsection{Step 1: GoAl DEFINITION “What IS THE PURPOSE?”}

In this step, the purpose and desired learnings of the study are decided, taking into account the intended audience and other relevant stakeholders. The aim of this step is to define the purpose and application of the study (sub-step 1.1), the study complexity (sub-step 1.2) and the time and resources available (sub-step 1.3). The study purpose and study complexity will be influenced by whether the study is carried out pre or post implementation. A pre-assessment will be prospective and more assumptions need to be made. However, the study will provide valuable knowledge at a time where it is easier to influence the PSS design and strategies. This step guides the assessment, in terms of how scenario-based the approach should be and the level of detail to be involved. As such, it may already in this step be decided if a 'full LCA' is 
applicable or if a 'screening LCA', based on more aggregated data, is more suitable. It is also decided whether the study needs to be ISO compliant.

\subsection{Step 2: PSS AND Reference SyStem exploration “What to compare?”}

In this step, the scope of the study is decided, along with a definition of the reference system. In sub-step 2.1, the reference system is decided in relation to the three scopes defined in Kjaer et al. (2016) (Figure 3):

- PSS consequences: system-level assessment, focused on analysing the changes caused by introducing the PSS and identifying all relevant substitutions.

- PSS comparison: compares the PSS with a predefined alternative, which can either be a non-PSS option (e.g. the traditional product-sale business model) or an alternative PSS solution (e.g. product-oriented vs. result-oriented PSS).

- PSS optimisation: evaluates different design options within an existing PSS.

Scope
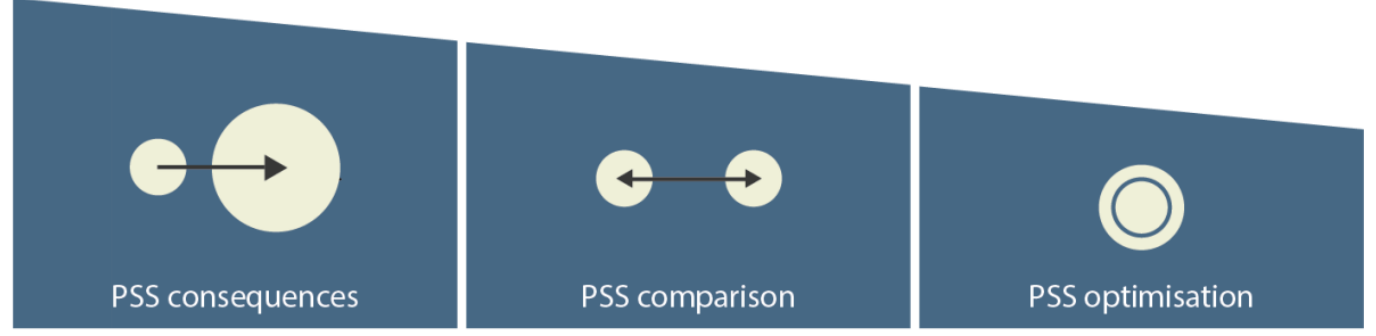

Purpose

System-level assesment

Scenario

assesment

PSS design option assesment

Reference system

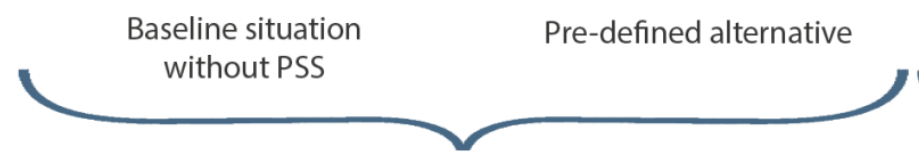

External reference system

Internal reference system

FIGURE 3: THREE SCOPES FOR ENVIRONMENTAL ASSESSMENT OF PSS

In sub-step 2.2, the reference system is explored, explicitly supporting a PSS consequences study scope. Specific attention is given to identifying the relevant product system(s) that the PSS substitutes. The relevant substitutions depend on what the PSS supports. Three types of PSS support are distinguished:

- Activity support: The PSS supports or replaces an activity on behalf of the customer. The reference system is the activity without the PSS support. The reference system exploration describes the activity without the PSS, and identifies which elements the PSS substitutes. For a result-oriented PSS that delivers a functional result, the PSS might substitute all product and service elements, while a productoriented PSS might focus on supporting specific tasks, often during the product operation (the use stage). Attention is given to whether or not other life cycle stages are indirectly affected, as this will affect the later system boundary definition (in sub-step 4.2). An example of an "activity support" is a laundry service for private households. The reference system is the activity of the households doing the laundry themselves, and only the use stage of the textiles is directly influenced by the PSS. 
- Product support: A product is supported through life cycle services (e.g. maintenance, upgrade and take-back services) or offered as a service (e.g. through pay-per-service-unit). The reference system is the product system without the PSS support. The reference system exploration describes the full life cycle of the substituted product system, and identifies how the PSS affects the life cycle. A productoriented PSS such as a take-back service might influence the lifetime or end-of-life treatment of the product. A use-oriented PSS such as product rental will shift product ownership from the user to the supplier, which might influence the product life cycle. An example of a "product support" PSS is a maintenance service, which can be offered as either an after-sale service (product-oriented PSS) or be part of a leasing/rental scheme (use-oriented PSS). Product maintenance can influence the resource consumption during use as well as the useful lifetime of the product.

- Platform support: Products and services are offered on a platform for customers to use (e.g. through subscriptions or short-terms rentals). The reference system is the situation without the PSS, encompassing all relevant substituted product systems. When a PSS is supporting a platform, e.g. a useoriented PSS such as a sharing system, the provider has limited control over the different product systems that the PSS substitute. The reference system exploration aims to identify these multiple product systems, which needs to be included in the assessment. An example of "platform support" is a car-sharing system within a city, where the PSS substitutes many different transport means such as private cars, rented cars, taxis, public transport, or even biking or walking.

In sub-step 2.3, the PSS strategy(ies) and its environmental impact reduction potentials is described. The purpose is to make a qualitative assessment of the PSS' potential to reduce environmental impacts compared to the reference system. Impact reduction potentials range from direct reductions stemming from resource efficiency during product use (e.g. through operational support or upgrade services) to indirect reductions, stemming from intensified product use (e.g. through product sharing) or product longevity (e.g. through maintenance or reuse). Lastly, impact reductions might come indirectly through shifts in products and services utilised (e.g. when a PSS delivers an 'optimised result' by utilising cleaner technologies) or through overall shifts in product systems (e.g. when a PSS enables that customers shift away from product systems with higher impacts).

In the last sub-step 2.4, the learnings and conclusions from the previous sub-steps are summarised to decide the systems to be analysed in terms of relevant PSS scenario variations and the reference system(s) they will be compared with.

\subsection{Step 3: Comparability Assessment “How to compare?"}

This step aims to ensure that the systems chosen for analysis actually are comparable and that they provide the same functionality. The common functionality is defined along with a definition of the functional unit (FU), upon which the comparison(s) will be based (sub-step 3.1). Criteria for defining the FU:

- The FU should describe the functional outcome in a measurable way, typically as a specification of its quantity (how much?), duration (for how long) and, if relevant, a location (where?).

- The FU should be encompassing enough to be able to capture the functionality of the PSS and each of the substituted product systems within the reference system.

- The FU should be descriptive and reflect the activities that the PSS encompasses. 
- It is important not to lock the FU onto a parameter that might change as a result of the PSS. If, for example, the frequency of the service is expected to change, this should be variable without having to change the FU. Instead, the amount of service needed will be reflected when specifying the reference flows (the amount of products and services needed to fulfil the functional unit).

Guidance for each of the three types of PSS support:

- Activity support: The FU can often be narrowed down to representing the activity affected by the PSS.

- Product support: The FU should be able to capture changes in the life cycle of the product system in focus.

- Platform support: The FU needs to capture all the substituted product systems in the reference system.

The systems are then subdivided into a specification, describing 'how' the functionality is provided (substep 3.2). Guidance for each type of PSS support:

- Activity support: overall activity is divided into sub-activities.

- Product support: all activities over the product life cycle are mapped.

- Platform support: all the product system constellations that the PSS substitute are listed.

The system sub-division is followed by an assessment of 'how well' the customer perceives the utility and value of the compared systems, in order to identify differences in performance, which might trigger rebound effects (sub-step 3.3). The purpose is to capture 'non-functional' performance characteristics to ensure that the comparison is carried out on an equal basis. While utility of a solution can be evaluated objectively, the actual value is a subjective judgement. Both utility and value are affected by consumption factors. Examples of consumption factors that might change between the PSS and its reference system are: money (if the PSS is more or less costly than the alternative), time (when the PSS is more or less time consuming) and access (when the PSS is more or less available).

Identifying and assessing relevant consumption factors will help to ensure that the systems are actually comparable from the perspective of the user - are the assumed substitutions likely to occur? Furthermore, differences in constrained consumption factors will likely trigger rebound effects which might entail that the actual impact savings are less than expected. A rebound effect can also be 'negative' (causing a doublenegative), resulting in what we have termed secondary benefits. Measuring the size and the environmental impacts associated with the rebound effect will often be out of scope of the study. However, a qualitative judgement will enable that measures can be taken in order to mitigate the rebound effect e.g. in the design process.

Figure 4 shows a PSS compared to a reference system. Processes that do not change in the PSS and the reference system will have the same impact (the dark part of the PSS bar). Avoided impacts stem from processes displaced by the PSS and induced impacts stem from processes added by the PSS. When the avoided impacts are greater than the induced impacts, the PSS can be said to result in impact savings, represented by the dotted area. Rebound effects (illustrated by the red arrow) will lead to a decrease in 
anticipated savings, while secondary benefits (illustrated by the green arrow) will lead to an increase in anticipated savings.

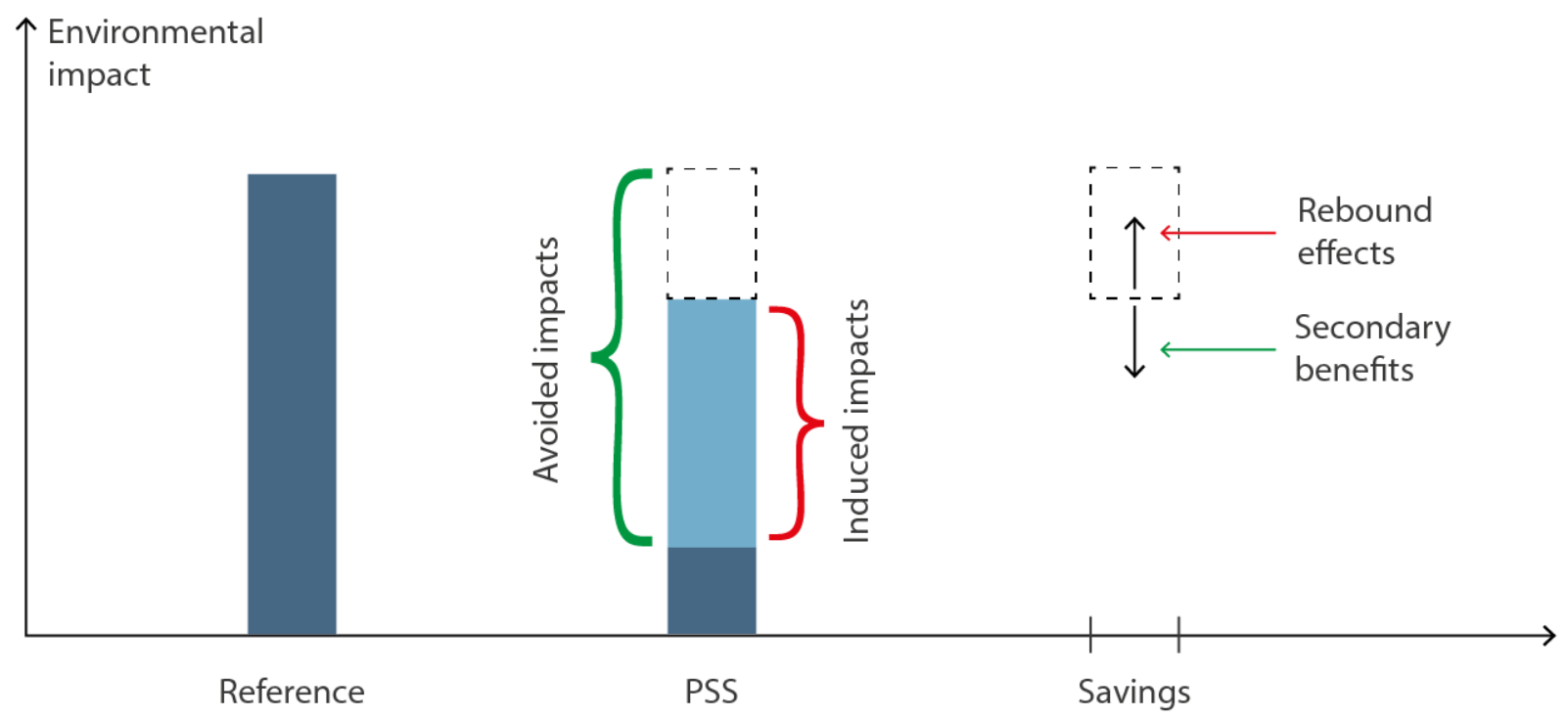

FIGURE 4: COMPARING A PSS WITH A REFERENCE SYSTEM IN TERMS OF ENVIRONMENTAL IMPACT.

\subsection{Step 4: Process MAPPIng “What to QuANTIFy?”}

The purpose of this step is to create an overview of the quantitative data that need to be gathered. Visual flowcharts (e.g. a process tree) may be utilised to create an overview of the included processes and may visualise which processes are induced (added) or avoided (displaced or reduced) (sub-step 4.1). Flowcharts are based on the system subdivision in sub-step 3.2. This is followed by specifying the system boundary, which delimits which processes are included in the assessment (sub-step 4.2). In terms of the reference system, a PSS might only influence one life cycle stage of the product life cycle (the use stage) but might indirectly influence the whole life cycle, which then needs to be included within the system boundary. If the PSS includes decisions between different end-of-use strategies, the system should be expanded to cover multiple product systems, since the product system(s) substituted by the second-hand product or material must be included in the assessment. Also for a PSS supporting a platform, it will often be necessary to include multiple product systems within the system boundary of the reference system. In terms of the PSS, It is emphasised that it is important not to leave out inputs that might be significant for the overall induced impacts of the PSS. Inputs that are often left out, under the assumption that they have insignificant contributions, include services such as administration, and capital goods such as infrastructure and buildings. However, for PSS such input might constitute a large part of the PSS induced impacts. Mapping of multifunctional processes (processes with more than one product/service output), should follow the ISO hierarchy of how to deal with processes shared with other product systems (ISO, 2006). Lastly, the impact categories that are going to be measured are decided based on which are relevant for the system in focus and the intended audience, also considering risks of trade-offs between impact categories (sub-step 4.3).

\subsection{Step 5: QuANTIFICATION “HOW to QuANTIFy?”}


The purpose of this step is to build the LCA model. Inventory data are gathered for all included processes (sub-step 5.1) and the quantitative results are generated (sub-step 5.2). Step 5 can in principle be done by following the life cycle inventory (LCI) phase and life cycle impact assessment (LCIA) phase, as described in ISO 14044. Since a PSS is often assessed pre implementation, includes numerous product systems and relies on many inputs in terms of services, products, and support systems, this will influence the data collection, which to a larger extent will have to be based on estimates, assumptions and secondary data (e.g. from LCA databases). While this might introduce uncertainty in terms of data precision, focusing on choosing the best representative data and modelling approach should help provide meaningful results.

\subsection{Step 6: INTERPRETATION AND RECOMMENDATIONS “WhAT TO CONCLUDE?”}

In this final step, the results are evaluated and presented, both quantitatively and qualitatively, highlighting the most important influencing parameters. First, the quantified results are evaluated in terms of their validity (sub-step 6.1). This sub-step might include completeness checks, sensitivity checks and consistency checks as described in ISO 14044. The result evaluation can be supported by a scenario analysis, where parameters are varied to find optimums or break-even cases, in order to argue under which circumstances the PSS is environmentally superior. Together with the qualitative results from step 2-4, the overall conclusions are then communicated to the intended audience (sub-step 6.2). Three main aspects should be highlighted (see also Figure 4):

- The PSS' substitutability (avoided impacts): Does the result depend on the PSS' ability to substitute specific products systems and has the study revealed any concerns about their substitutability?

- The PSS' dependencies (induced impacts): Does the PSS depend on support systems, infrastructure and services, which are added, compared to the reference system? Are any of these processes left out of the assessment, which could jeopardize the results?

- Rebound effects: Is there a risk that the PSS will increase the demand for the products/services (direct rebound effect) or other consumption (indirect rebound effect)?

Finally, if included in the study purpose, a set of recommendations might be formulated, such as how to optimise the PSS design, guide the PSS strategies in order to ensure proper adoption, and mitigate rebound effects (sub-step 6.3). This finale sub-step is considered optional.

\section{CASE EXEMPLIFICATION}

In the following, the guidelines are demonstrated using three hypothetical PSS case examples, representing the three study scopes and the three types of PSS support, respectively. To account for space limits, all three cases have been substantially simplified and the following steps are not individually elaborated for each case:

- Sub-step 1.3: Time and resources. For all cases, limited time and resources are assumed and what may be defined as a 'screening level LCA' is applied.

- Sub-step 4.3: Impact categories. For Case 1 and 2, global warming (measured in $\mathrm{CO}_{2} \mathrm{e}$ ) is the impact category considered. However, for case 3 , the trade-off between global warming and eco-toxicity is of concern and both impact categories are therefore included. It should be noted that a full assessment would normally include multiple impact categories. 
- Step 5: Quantification. Upstream emission data for greenhouse gases (GHGs) are based on processes in the Ecolnvent database and/or the hybrid Input-Output model FORWAST (for more information, see Kjaer et al. (2015)), and direct emission data for fuel combustion is based on calorific value and $\mathrm{CO}_{2}$ content for the fuel type in question. The modelling approach for ecotoxicity in case 3 is described in Pagoropoulos et al. (2017).

- Sub-step 6.1: Result evaluations. No completeness, sensitivity or consistency checks are included and no further scenarios are assessed. For case 3, see Pagoropoulos et al. (2017) for a detailed analysis.

\subsection{CASE 1: BIKE-SHARING SYSTEM}

A municipality of a large city is offering a public, electrical bike-sharing system called 'BikeNow' for the city commuters, locals and tourists with the purpose of reducing pollution within the city. Prior to the introduction of BikeNow, the municipality conducted a survey, asking the city commuters to state how they would prioritise between different modes of transport, if they had the option to commute by public electrical bikes. Based on this survey, the municipality would like to know how the carbon footprint from commuting would change for the commuters stating that they would change to BikeNow.

\section{Step 1.}

1.1: The purpose of the study is to support the municipality (the intended audience) to quantify whether or not BikeNow would reduce GHG emissions from the target group commuters. This will help support decisions on how BikeNow should be implemented.

1.2: Since the study is done pre implementation, it is based on assumptions about user behaviour based on the statements in the survey. Study complexity is further influenced by the fact that the bike-sharing system substitutes many different transport modes. However, focusing only on commuters as a target group and not locals and tourists reduces the study complexity.

\section{3: N/A}

\section{Step 2.}

2.1: The reference system is external and defined as the baseline situation without the PSS, and the scope is therefore PSS consequences.

2.2: The PSS support is platform support and the PSS substitutes multiple product systems, since it influences many commuting options.

2.3: The PSS' potential to reduce environmental impact comes indirectly from the sharing platform, as it enables product system substitutions (when commuters change from one transport-mode to another, which has less environmental impacts).

2.4: The systems to be analysed are the current combination of transport modes for the commuters stating they would change to the bike-sharing system (the reference system) and the new combination of transport modes, including BikeNow (the BikeNow scenario).

\section{Step 3.}


3.1: The functionality is to provide transport and the $\mathrm{FU}$ is defined as 5,000 citizens commuting for one average month $=>200,000$ trips (corresponding to 40 trips/month/user). As such, the whole commuting distance is taken into account and not only the distance covered by BikeNow. The 5,000 citizens correspond to $3 \%$ of the ca. 170,000 daily city commuters and is estimated based on the survey result.

3.2: The system subdivision specifies the commuting options in the reference system and in the bikesharing scenario as shown in Table 3. Note, that in the survey, no distinction between metro and bus was made.

3.3: Examples of important consumption factors to consider are: time, convenience and money. If the commuting option is more time consuming or less convenient, e.g. in bad weather, the substitution might not occur. An indirect rebound effect comes from users who save money and will increase other types of consumption.

TABLE 3: SYSTEM SUBDIVISION (E.G. 25\% OF USERS CHANGE FROM TRAIN + OWN BIKE TO TRAIN + BIKE-SHARING SYSTEM + WALKING). ITALIC MARKINGS ARE THE PART OF THE TRIP THAT IS UNCHANGED.

\begin{tabular}{|l|l|l|l|}
\hline Users & $\begin{array}{l}\text { Distribution } \\
(\% \text { of trips) }\end{array}$ & Reference system & Bike-sharing scenario \\
\hline A & $25 \%$ & Train + own bike & Train + bike-sharing system + walking \\
\hline B & $45 \%$ & Train + metro/bus + walking & Train + bike-sharing system + walking \\
\hline C & $10 \%$ & Car & Train + bike-sharing system + walking \\
\hline D & $20 \%$ & Train + walking & Train + bike-sharing system + walking \\
\hline
\end{tabular}

Step 4.

4.1: Based on the system sub-division, a visual flowchart (process tree) is created, breaking down the FU into the different commuting options (Figure 5a) showing which are induced (added) and avoided (displaced or reduced). Each commuting option represents a product system with a life cycle on its own (subdivision not shown in the process tree). Walking is assumed emission free. The process for BikeNow is further subdivided into electric bike (including battery) production \& end-of-life, and bike operation (includes bike maintenance, administration, docking stations, road use and electricity production).

4.2: Processes that do not change between the compared systems are eliminated, leaving only the part of the commuting distance that would change to be included within the system boundary, see Table 4.

\section{3: N/A.}

TABLE 4: REFERENCE FLOWS OF THE TWO SCENARIOS. E.G. IN AVERAGE, COMMUTERS CHANGING FROM OWN BIKE, HAD A TRANSPORT DISTANCE OF 3.5 KM. AFTER CHANGING TO BIKE-SHARIMNG SYSTEM, THEY WOULD USE IT FOR 3.3 KM AND WALK THE LAST 0.2 KM.

\begin{tabular}{|l|l|l|l|l|l|}
\hline \multirow{2}{*}{$\begin{array}{l}\text { User } \\
\text { distribution } \\
\text { (\% of trips) }\end{array}$} & \multicolumn{2}{|c|}{ Reference system } & \multicolumn{3}{c|}{ Bike-sharing scenario } \\
\cline { 2 - 6 } & Transport mean & $\begin{array}{l}\text { Average } \\
\text { distance }(\mathrm{km})\end{array}$ & Train $(\mathrm{km})$ & $\begin{array}{l}\text { Bike-sharing } \\
\text { system }(\mathrm{km})\end{array}$ & Walking (km) \\
\hline $25 \%$ & Own bike & 3.5 & - & 3.3 & 0.2 \\
\hline $45 \%$ & Metro/bus & 3.3 & - & 3.3 & - \\
\hline $10 \%$ & Car & 12 & 8.5 & 3.3 & 0.2 \\
\hline $20 \%$ & Walking & 0.7 & - & 0.5 & 0.2 \\
\hline
\end{tabular}


Step 5. N/A

\section{Step 6.}

6.1: N/A

6.2: Results show that for 5,000 commuters using BikeNow, a total saving of 52 ton $\mathrm{CO}_{2}$ e would be achieved, corresponding to a $68 \%$ decrease in emissions for this segment of commuters. The savings come from the commuters changing from car and metro/bus while changing from own bike and walking increase emissions. As such, the sharing system's potential to save emissions depends on its ability to substitute cars and public transport means. The assessment on utility and value in sub-step 3.3 identified increased time consumption and inconvenience (influenced by e.g. weather conditions, bike availability etc.) as relevant consumption factors. Further scenarios and sensitivity checks should be developed to account for variations, e.g. by assuming a lower adoption during winter months. For the BikeNow system, bike production \& end-of-life account for approximately $50 \%$ of the emissions, and bike operation accounts for the remaining $50 \%$, with maintenance being the dominant contributor. It is recommended to follow up with an assessment post implementation and collect more representative data on the bike-sharing system and its actual use, including its users' alternative transport patterns.

6.3: If targeting commuters, recommendations include e.g. placing charging stations near train stations and areas with office buildings and large companies to make commuting journeys as efficient as possible. For an improved design of the BikeNow system, emphasis should be on using durable bikes with low maintenance need. 


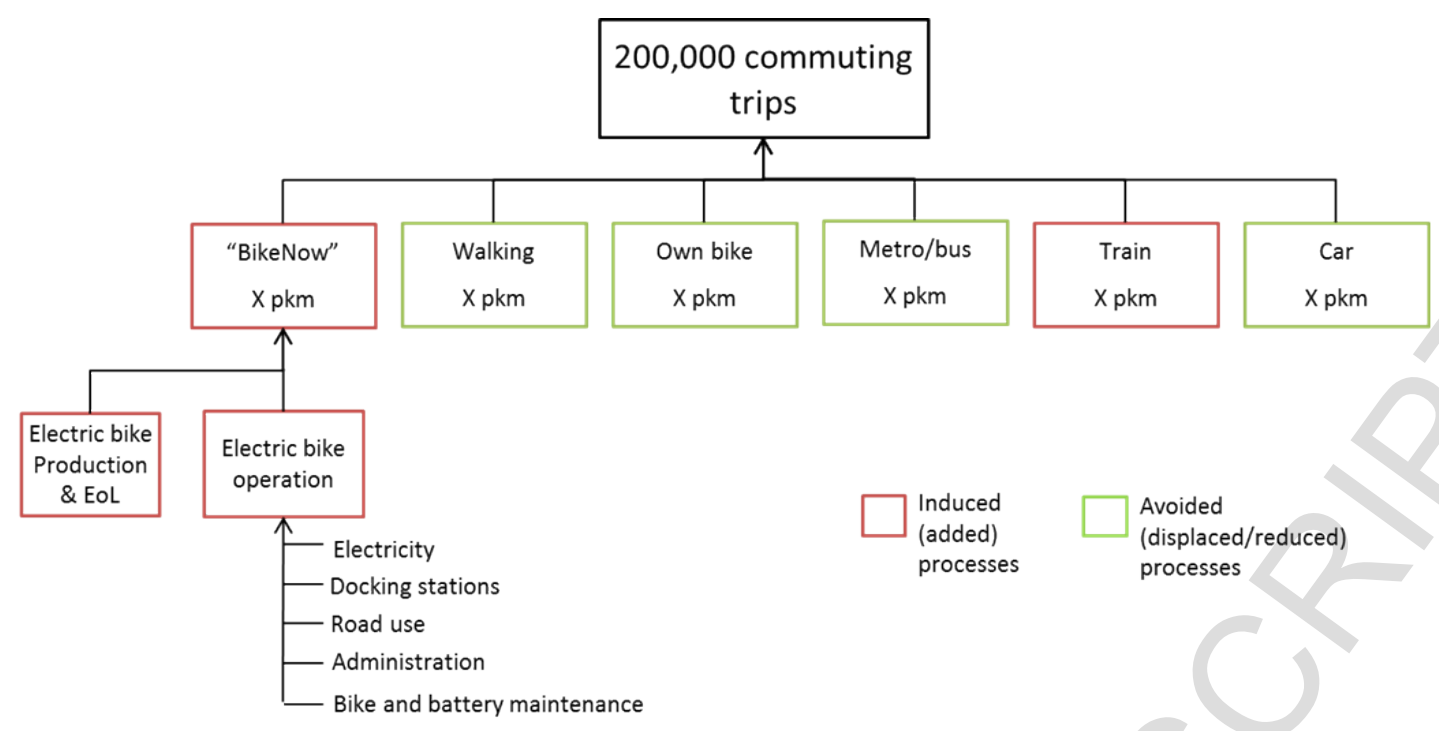

a) Process-tree for bike-sharing system. Only processes that change between the compared scenarios are shown and only "electric bike operation" is further detailed in the diagram

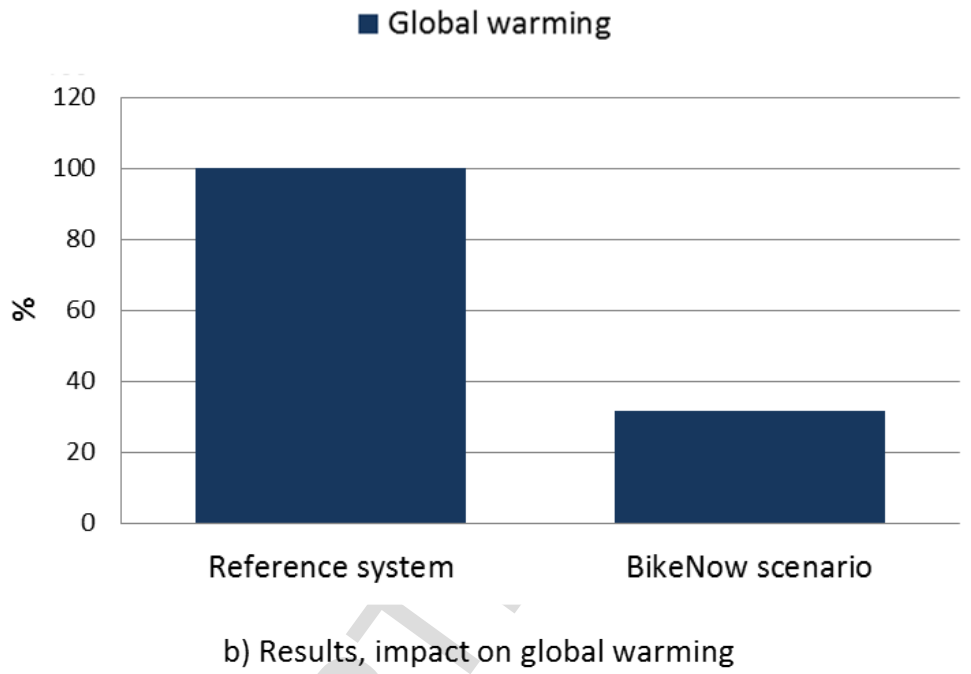

FIGURE 5: FLOWCHART AND RESULTS FOR BIKE-SHARING SYSTEM

\subsection{CASE 2: SHARED LAWNMOWER}

Eight households in a residential area have purchased a PSS involving a shared, large-sized, sit-on-top lawnmower and repair-service contract for 10 years. The PSS is paid for through common expenses in the house-owners' association. After two years, it is evaluated whether or not the PSS has resulted in impact savings.

\section{Step 1.}

1.1: The purpose is to do an environmental assessment post implementation to evaluate whether the PSS has been a success or not. The intended audience is the PSS provider, who will use the results to further develop their business model. 
1.2: Study complexity is relatively low, since data are available about the use of the PSS and only one application scenario is considered.

1.3: N/A

Step 2.

2.1: The reference system is external and defined as each household owning a private normal-sized lawnmower. The study is a scenario assessment and the scope is thus PSS comparison.

2.2: The PSS involves supporting a product over its life cycle, thus the PSS support is defined as product support and the substituted product system is the normal-sized lawnmower. Based on interviews with the households, it is discovered that only four of the households still use the PSS. The other four households have chosen to go back to using their own lawnmower.

2.3: The PSS' potential to result in environmental impact savings come from optimised product utility through intensified use, as a result of the product sharing strategy.

2.4: The systems to be analysed are: a) the situation if each households had owned and used their own individual normal-sized lawnmower (reference system); b) the situation if the PSS were used by all households as assumed before implementation (PSS1); and c) the current situation two years after the PSS was purchased (PSS2).

Step 3.

3.1: The functionality is to keep the grass of the lawns below a desired length and for the two systems the common FU is defined as: Mowing of $4,800 \mathrm{~m}^{2}$ lawn (corresponding to 8 households) in 10 years.

3.2: The systems are subdivided into activities over the product life cycle and are for this study limited to: lawnmower production \& end-of-life, repair service and actual mowing during use.

3.3: Identified consumption factors of relevance include: money (potential savings in total cost of ownership will lead to more consumption), time (the large-sized lawnmower is faster), space (sharing one lawnmower will leave space in the garage), access (risk of no availability if the shared product is in use) and comfort (the normal-sized lawnmower needs to be walked around, while the large-sized is a sit-on-top type).

\section{Step 4.}

4.1: Based on the system subdivision, a flowcart (process tree) is created (Figure 6a) showing which processes are induced (added) and avoided (displaced or reduced).

4.2: The system boundary has been limited to the processes of lawnmower production \& end-of-life, the repair service and the gasoline production and combustion during use. Three important changes in flows occur between the PSS1 and PSS2 scenarios (Table 5): In PSS1 (before implementation), it was assumed that all households would use the PSS as a substitute for their own lawnmower, the use pattern was assumed to be the same as when the household had their own private lawnmower ( 20 times per year), and the need for repair-service was assumed to be every second year. However, the actual situation after two 
years is that four of the households have stopped using the shared lawnmower and now use their own lawnmower instead. The main reason is the lack of flexibility and availability - all too often, when needed, the shared lawnmower would be in use by someone else. Furthermore, the four households still using the PSS now mow the lawn 30 times per year on average instead of 20, mainly because the large lawnmower is faster and (to some users) more 'fun'. Finally, the need for repair-service turned out to be every year, not every second year.

4.3: N/A.

TABLE 5: SHARED LAWNMOWER. PRODUCT SYSTEM SPECIFICATIONS FOR THE THREE SCENARIOS.

\begin{tabular}{|l|l|l|l|}
\hline & $\begin{array}{l}\text { a) Reference system } \\
8 \text { households use their } \\
\text { own normal size } \\
\text { lawnmower }\end{array}$ & $\begin{array}{l}\text { b) PSS1 } \\
8 \text { households share large } \\
\text { lawnmower }\end{array}$ & $\begin{array}{l}\text { c) PSS2 } \\
\text { 4 households (group A) shares large } \\
\text { lawnmower, 4 households (group B) } \\
\text { uses their own normal size } \\
\text { lawnmower }\end{array}$ \\
\hline Use pattern & $\begin{array}{l}\text { 20 times per year for each } \\
\text { household }\end{array}$ & $\begin{array}{l}\text { 20 times per year for each } \\
\text { household }\end{array}$ & $\begin{array}{l}\text { Group A: 30 times per year. } \\
\text { Group B: 20 times per year. }\end{array}$ \\
\hline $\begin{array}{l}\text { Lawnmower } \\
\text { specifications }\end{array}$ & $\begin{array}{l}\text { Normal size (34kg) } \\
\text { Product lifetime: } 5 \text { years } \\
\text { Gasoline use: 11. per hour } \\
\text { Average operational time } \\
\text { per lawn: } 30 \text { min. }\end{array}$ & $\begin{array}{l}\text { Large size (227kg) } \\
\text { Product lifetime: } 10 \text { years } \\
\text { Gasoline use: 4l. per hour } \\
\text { Average operational time } \\
\text { per lawn: 10 min. }\end{array}$ & $\begin{array}{l}\text { Group A: Same as a) } \\
\text { Group B: Same as b) }\end{array}$ \\
\hline $\begin{array}{l}\text { Repair service } \\
\text { intervals }\end{array}$ & $\begin{array}{l}\text { After 2.5 years (2 times } \\
\text { per FU) }\end{array}$ & $\begin{array}{l}\text { Every second year (5 times } \\
\text { per FU) }\end{array}$ & $\begin{array}{l}\text { Group A: Every year (9 times per FU) } \\
\text { Group B: Same as a) }\end{array}$ \\
\hline
\end{tabular}

Step 5: N/A

Step 6.

$6.1 \mathrm{~N} / \mathrm{A}$

6.2: Results are shown in Figure 6b. Even though the PSS1 scenario would increase gasoline use, the avoided production of normal-sized lawnmowers would reduce GHG emissions by approximately 30\% compared to the reference system. However, for PSS2, which was the actual situation after two years, the result is an increase by $12 \%$, due to increased gasoline use and repair service as well as an unfulfilled potential of normal-sized lawnmower displacement.

6.3: The main recommendation is to make the PSS more attractive for all households. Another idea that came up from one of the households was to let one user mown all the lawns in exchange of a small salary. 


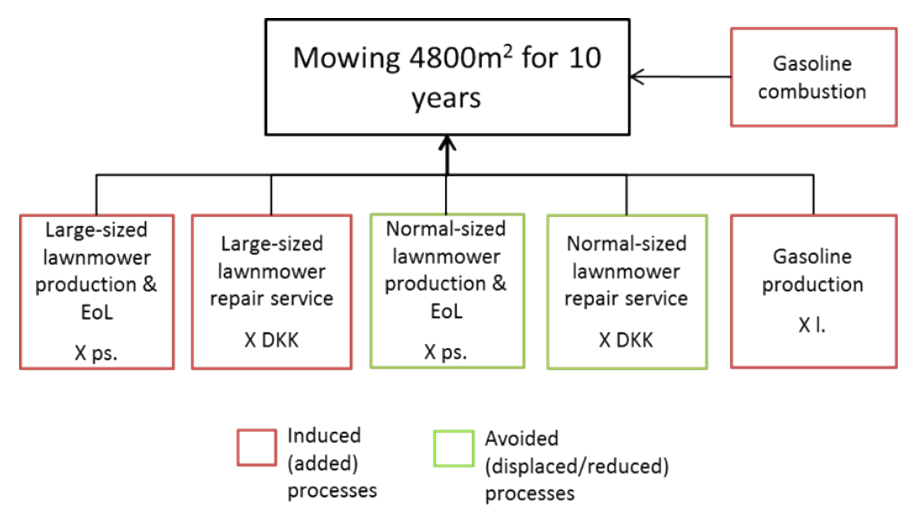

a) Process-tree for shared lawnmower PSS. Only processes that change between the compared scenarios are shown

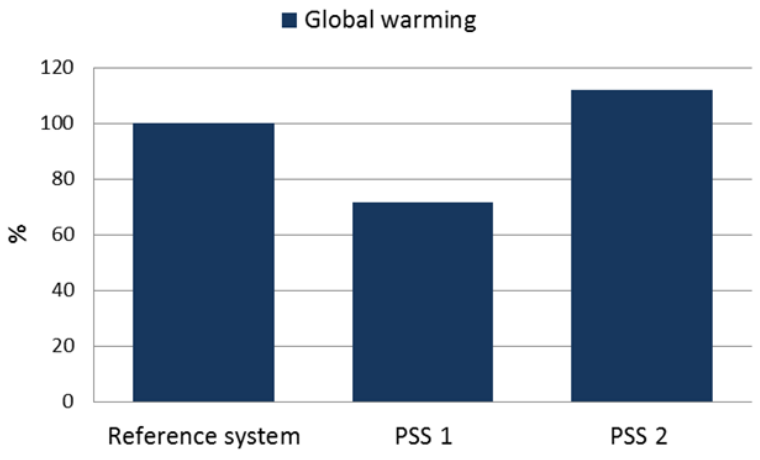

b) Results, impact on global warming

FIGURE 6: FLOWCHART AND RESULTS FOR SHARED LAWNMOWER PSS

\subsection{CASE 3: HULL CLEANING SERVICE OF TANKER SHIPS}

To prevent biofouling, where marine organisms accumulate on a ship's hull and causes increased fuel consumption (known as 'fuel penalty'), tanker ships are equipped with a coating system, in this case a biocidal antifouling paint with a copper compound as the active ingredient that repels fouling. Every five years, the ship is repainted while in dry-dock (out of operation for periodic maintenance). However, the coating system is often not enough to prevent fouling and in-water hull cleanings are needed, where a team of divers clean the hull with brushes. The PSS under study is a hull management system offered by the paint provider. The provider monitors the hull and suggests when and how a hull cleaning should be conducted, to ensure that the coating system performs. The PSS provider wants to optimise the PSS by implementing a performance agreement in which hull cleanings are initiated every time the fuel penalty is above a certain threshold. Data are gathered for a group of tanker ships. With the performance agreement, the number of cleanings would change from two to six times during the five-year period between dry-docks and their timing would be optimised.

\section{Step 1}

1.1: The purpose is to evaluate how the optimised PSS influence the impact on global warming and ecotoxicity compared to the existing hull management scheme. The intended audience is the PSS provider, who will use the results to further develop the PSS in collaboration with the shipowner.

1.2: Data uncertainty in general is relatively high, due to high variations in operational sailing patterns, how hull cleanings are performed and how paint is removed after five years of operation. To focus the study, the data are based on a selected group of tanker ships and only one application scenario is considered here. See Pagoropoulos et al. (2017) for a more detailed study.

\section{3: N/A.}

\section{Step 2}


2.1: The scope is defined as PSS optimisation, since the reference system is the existing hull management scheme.

2.2: The PSS is the hull management, and the PSS support is defined as activity support, which only directly influences the operational life cycle stage of the paint as well as the ship.

2.3: The PSS' potential to result in environmental impact savings comes from direct resource efficiency as a result of the operational support (reduced fuel consumption of the ship).

2.4: The systems to be analysed are: a) the hull management PSS where hull cleanings are initiated on an ad hoc basis based on periodic inspections (average twice per five years); b) the optimised PSS, where hull cleanings are initiated when fuel penalty is above a certain threshold (average six times per five years).

\section{Step 3.}

3.1: The functionality of the PSS is to monitor and clean the ship hull, and the FU is defined as: Monitoring and cleaning the hull of a medium tanker vessel throughout the five year life cycle of the paint.

3.2: The activity is divided into sub-activities, which include paint application, ship operation, hull cleanings and paint removal.

3.3: The main risk of rebound effect identified is that the fuel savings might work as an incentive for the shipowner to increase speed, which would alleviate the impact saving.

\section{Step 4.}

4.1: The flowchart in the form of a process tree is shown in Figure 7a.

4.2: The system boundary has been limited to the processes that change as a result of the optimised PSS, which excludes the paint application and paint removal. For the impact category global warming, avoided impacts stem from the decrease in fuel consumption, which reduces GHG emissions from both fuel production and fuel combustion. Induced impacts come from the upstream impacts associated with the actual hull cleaning activity. To capture all upstream impacts associated with the hull cleaning activity and ensure a high level of system boundary completeness, calculations are done in a top down manner using a hybrid input-output model as described in Pagoropoulos et al. (2017). For the impact category eco-toxicity, induced impacts stem from the increase in copper being removed during hull cleaning, which affects the marine eco-toxicity.

\subsection{N/A.}

\section{Step 5: N/A.}

\section{Step 6.}

\section{$6.1 \mathrm{~N} / \mathrm{A}$.}

6.2: Results are shown in Figure 7b. Even when including induced impacts from the added hull cleanings, the optimised PSS would increase the saved GHG emissions by approximately $50 \%$ compared to the existing 
PSS. However, the impact on eco-toxicity would increase by $80 \%$. As such, there is a trade-off between impact categories, which would not have been revealed if only focusing on global warming.

6.3: It is recommended to implement the optimised PSS, but to ensure that hull cleanings are done as gentle as possible to reduce impacts on the local marine environment.

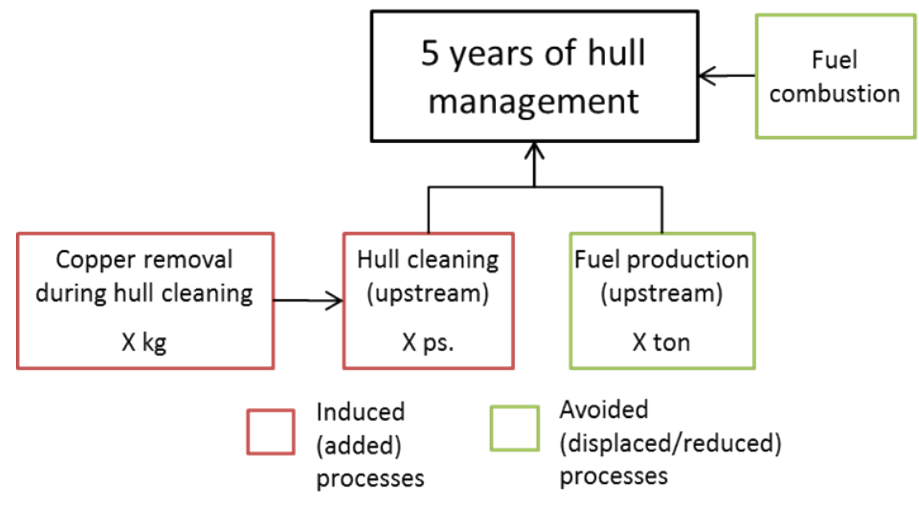

a) Process-tree for hull cleaning PSS. Only processes that change between the compared scenarios are shown

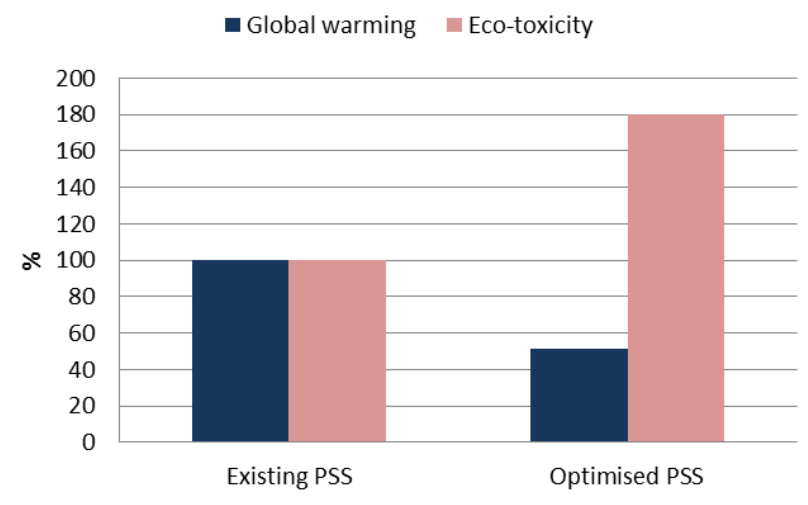

b) Results, optimised hull cleaning PSS

FIGURE 7: FLOWCHART AND RESULTS FOR HULL CLEANING PSS

\subsection{DISCUSSION ON CASE EXEMPLIFICATION}

The three presented cases exemplify how the guidelines assist the relevant challenges depending on the study scope and the type of PSS support. For the bike-sharing system, the PSS supported a platform and the ability to enable impact savings depended on which transport modes the bike-sharing system was able to substitute. Assuming that the bike-sharing system would substitute the same type of product system (e.g. privately owned bike) would be a false assumption. It was essential to determine which and to what extent different transport modes would be substituted. As such, the case illustrates the importance of a reference system exploration, supported by the guidelines in Step 2. The case also illustrated the importance of defining a broad FU that would capture the full commuting distance (as emphasised in Step 3 of the guidelines). Only looking at the distance covered by the BikeNow system would not capture changes in depending transport modes. The case showed that consumption factors could influence if and to what extent commuters would adopt and use the bike-sharing system as a substitute for other transport modes e.g. a private car, which can be considered more convenient (especially in bad weather) and is always available. The case exemplifies an assessment done pre implementation, which includes assumptions and should be supplemented by scenario analyses and sensitivity checks. Furthermore, an assessment post implementation would be essential to determine the actual user behaviour of the system and check potential misalignments between expectations and reality.

For the shared lawnmower PSS, its ability to enable impact savings depended on the ability to substitute the individual ownership and mitigate rebound effects. The guidelines emphasise the importance of supplementing the FU definition with a comparability assessment, and for case 2, this was essential to determine the PSS' substitutability and causes for rebound effects. Furthermore, this case study 
exemplified the relevance of complementing an assessment pre implementation with an assessment post implementation to identify and measure the consequences of a rebound effect.

For the hull cleaning PSS, the PSS supported an activity with the purpose of reducing fuel consumption. As such, avoided impacts were easily identified, however the PSS induced impacts had to be thoroughly assessed, with a focus on ensuring system boundary completeness to determine if net impact savings could be expected. The guidelines emphasise the importance of including service inputs when defining the system boundary in Step 4. Furthermore, the case showed the importance of including relevant impact categories for the system in question, to identify potential trade-offs. For case 1 and 2, the focus on a single indicator (global warming) can be seen as a limitation.

\section{CONCLUSIONS AND FUTURE WORK}

In this article, we have proposed guidelines for evaluating the environmental performance of PSS based on the LCA methodology. The focus of the guidelines is to support the study scoping in terms of: defining the reference system in order to identify relevant systems to be analysed; assessing the comparability between the systems in supporting the functional unit definition; and ensuring that processes induced by the PSS are sufficiently included. Table 6 summarises how the guidelines support the requirements formulated in section 3. 


\begin{tabular}{|c|c|}
\hline $\begin{array}{l}\text { Guideline } \\
\text { requirements }\end{array}$ & How the guidelines support the evaluation \\
\hline $\begin{array}{l}\text { \#1 Focus on study } \\
\text { scoping }\end{array}$ & The goal and scope definition phase is divided into four subsequent steps. \\
\hline $\begin{array}{l}\text { \#2 Support reference } \\
\text { system definition }\end{array}$ & $\begin{array}{l}\text { Supported by step } 2 . \\
2.1 \text { Study scope: The distinction between the three scopes (PSS optimisation, PSS } \\
\text { comparison and PSS consequences) create an awareness that the reference system is not a } \\
\text { given for PSS, and help the user reflect on how the profile of the reference system fits with } \\
\text { the study purpose. } \\
2.2 \text { PSS support: The classification of PSS support (activity support, product support, platform } \\
\text { support) enables to distinguish between different types of PSS and the product systems (or } \\
\text { part of product system) they substitute. } \\
2.3 \text { PSS potential: By identifying the impact reduction potential and link it to the PSS } \\
\text { strategy, the user needs to reflect on how the PSS is assumed to changes the reference } \\
\text { system. }\end{array}$ \\
\hline $\begin{array}{l}\text { \#3 Support functional } \\
\text { equivalence }\end{array}$ & $\begin{array}{l}\text { Supported by step } 3 . \\
\text { The guidelines support the user to define an appropriate FU that is broad enough to remain } \\
\text { constant between the compared systems to be analysed. The FU definition is accompanied } \\
\text { by a system sub-division, taking into account the type of PSS support defined in sub-step } 2.2 \text {. } \\
\text { Lastly, the FU is accompanied by a comparability assessment in terms of utility and value, } \\
\text { which help identify consumption factors that can trigger rebound effects to allow for } \\
\text { mitigation strategies to be incorporated. }\end{array}$ \\
\hline $\begin{array}{l}\text { \#4 Support system } \\
\text { boundary definition }\end{array}$ & $\begin{array}{l}\text { Supported by step } 4 . \\
\text { The process mapping is based on the system subdivision, which should mitigate that } \\
\text { important processes are left out of the assessment. The guidelines emphasise not to cut off } \\
\text { processes that might entail a significant part of the PSS induced impacts. }\end{array}$ \\
\hline $\begin{array}{l}\text { \#5 Support different } \\
\text { approaches }\end{array}$ & $\begin{array}{l}\text { Supported in different steps. } \\
\text { Step 1: It is part of the study goal to determine whether the study is done pre or post } \\
\text { implementation and to consider the necessary level of detail for the assessment, taking into } \\
\text { account desired learnings, relevant application scenarios, data availability, and time and } \\
\text { resources. } \\
\text { Step 5: The data gathering process is supported by focusing on the processes that have the } \\
\text { largest influence on the results and to allow for a relatively high uncertainty in terms of data } \\
\text { precision to allow for multiple scenario assessments. The guidelines do not dictate which } \\
\text { impact categories should be included or how the impact assessment should be made, but } \\
\text { emphasises that risks of trade-offs between impact categories should be considered. }\end{array}$ \\
\hline $\begin{array}{l}\text { \#6 Focus on scenario- } \\
\text { approach and } \\
\text { qualitative learnings }\end{array}$ & $\begin{array}{l}\text { This is supported in different steps. } \\
\text { Step 1: The desired learnings should be stated. } \\
\text { Step 2: The systems to be analysed is defined along with recommendations on when to } \\
\text { include multiple scenarios for both the PSS and the reference system. } \\
\text { Step 6: The result communication focuses on providing not only the quantitative result, but } \\
\text { also the qualitative learnings gathered during step 2-4. }\end{array}$ \\
\hline
\end{tabular}

In order to support the application of the guidelines, an extended and detailed User Guide targeting practitioners has been developed (Kjaer et al., 2017). The User Guide contains a general introduction to PSS and the motivation for environmental evaluations, after which each guideline step is explained in a prescriptive manner. The main text is supported by boxes containing tips, examples and supplementary information. For each step it is stated which of the three competence profiles (strategic decision-maker, PSS designer and LCA practitioner) are needed, and each step ends with a list of summarising questions. 
The main limitation of the research presented in this article is the limited test of the proposed guidelines into real cases, covering the full complexity of real-life PSS case studies. Furthermore, because the guidelines are generic, industry specific considerations were not taken into account. This makes the guidelines context-independent but at the same time also requires that sufficient translation into industry specific contexts is performed.

Future work includes evaluating the guidelines through full case applications, as well as continued expert and user feedback. Furthermore, the following suggestions from experts and users during the guideline development process have yet to be implemented and will require additional research:

- Extended guidance on how to use scenario, dynamic and prospective modelling approaches to assess different PSS variations and systemic consequences.

- Better, structured approaches to identify, assess and quantify rebound effects.

- Improvement of existing LCA databases to allow for better inclusion of services.

- Compare and position the guidelines in relation to other guidelines (e.g. EU PEF guidelines, PAS2050 and the GHG Protocol).

As such, future work should not only focus on applying the guidelines, but also on improving and extending them by supplementary methodology development as well as stakeholder specific guidance.

The proposed guidelines do not solve all the challenges that exist for evaluating PSS through LCA. A study will not be able to capture all application scenarios, assumptions will always have to be made and rebound effects will inevitably occur. However, by applying the guidelines, the risk of biased results should be reduced and hopefully the guidelines will inspire more quantitative studies that move beyond the proof-ofconcept stage and evaluate the actual changes caused by a PSS, to further enlighten under which circumstances PSS lead to environmental improvements. More quantitative studies could assist decisionmaking e.g. when developing PSS business models and choosing between a product-, use- or resultoriented PSS. Lastly, the need for quantitative assessments done both pre and post implementation is acknowledged. Pre-assessments can assist decision-making at a time where the PSS design and strategies can be influenced and post-assessments can be valuable to determine the actual consequences of a change and help prove or disprove if avoided impacts are in fact realised and rebound effects mitigated.

\section{ACKNOWLEDGEMENT}

The authors would like to thank the TORM Foundation for its financial support. We would also like to acknowledge the support from PSS and LCA experts for their support in developing the guidelines.

\section{REFERENCES}

Amaya, J., Lelah, A., Zwolinski, P., 2014. Design for intensified use in product-service systems using lifecycle analysis. J. Eng. Des. 1-23.

Annarelli, A., Battistella, C., Nonino, F., 2016. Product service system: A conceptual framework from a systematic review. J. Clean. Prod. 139, 1011-1032.

Bech, N.M., Birkved, M., Charnley, F., Kjaer, L.L., Pigosso, D.C.A., Hauschild, M.Z., McAloone, T.C., Moreno, M.A., Submitted. Evaluating the environmental performance of a circular business model for Merino 
wool next-to-skin garments. The case of Armadillo Merino. J. Text. Inst.

Bennett, E.B., Graedel, T.E., 2000. 'Conditioned Air': Evaluating an Environmentally Preferable Service. Environ. Sci. Technol. 34, 541-545.

Bocken, N.M.P., Short, S.W., Rana, P., Evans, S., 2014. A literature and practice review to develop sustainable business model archetypes. J. Clean. Prod. 65, 42-56.

Bonvoisin, J., Lelah, A., Mathieux, F., Brissaud, D., 2014. An integrated method for environmental assessment and ecodesign of ICT-based optimization services. J. Clean. Prod. 68, 144-154.

Carrano, A.L., Pazour, J.A., Roy, D., Thorn, B.K., 2015. Selection of pallet management strategies based on carbon emissions impact. Int. J. Prod. Econ. 164, 258-270.

Chun, Y.-Y., Lee, K.-M., 2017. Environmental impacts of the rental business model compared to the conventional business model: a Korean case of water purifier for home use. Int. J. Life Cycle Assess. 22, 1096-1108.

CONCITO, 2012. Carbon Footprint - den ideelle opgørelse og anvendelse. Copenhagen, Denmark.

Dreijer, L.S., Birkved, M., Howard, T.J., Bey, N., 2013. The sustainability effects of Product/Service-System design validated, in: Proceedings of the Sustainable Buildings - Construction Products and Technologies: Collection of Full Papers. pp. 500-535.

European Commission, 2010. International Reference Life Cycle Data System (ILCD) Handbook - General guide for Life Cycle Assessment - Detailed guidance, First edit. ed. Publication Office of the European Union, Luxembourg.

Firnkorn, J., Müller, M., 2012. Selling Mobility instead of Cars: New Business Strategies of Automakers and the Impact on Private Vehicle Holding. Bus. Strateg. Environ. 21, 264-280.

Firnkorn, J.J., Müller, M., Mueller, M., 2011. What will be the environmental effects of new free-floating car-sharing systems? The case of car2go in Ulm. Ecol. Econ. 70, 1519-1528.

Gill, J., Johnson, P., 2010. Research methods for managers, 4th ed. SAGE Publications Ltd, London.

Global e-Sustainability Initiative, 2010. Evaluating the carbon-reducing impacts of ICT: An assessment methodology.

Gottberg, A., Longhurst, P.J., Cook, M.B., 2010. Exploring the potential of Product Service Systems to achieve household waste prevention on new housing developments in the UK. Waste Manag. Res. 28, 228-35.

Haapala, K.R., Brown, K.L., Sutherland, J.W., 2008. A life cycle environmental and economic comparison of clothes washing product-service systems, in: Transactions of the North American Manufacturing Research Institution of SME. Monterrey; Mexico, pp. 333-340.

Haase, R.P., Pigosso, D.C.A., McAloone, T.C., 2017. Product/Service-System Origins and Trajectories: A Systematic Literature Review of PSS Definitions and their Characteristics. Procedia CIRP 64, 157-162.

ICCA and WBCSD, 2013. Addressing the Avoided Emissions Challenge: Guidelines from the chemical industry for accounting for and reporting greenhouse gas (GHG) emissions avoided along the value chain based on comparative studies. 
ISO, 2006. ISO 14044 International Standard, Environmental management - Life cycle assessment Requirements and guidelines. International Organisation for Standardization, Geneva, Switzerland.

Kerr, W., Ryan, C., 2001. Eco-efficiency gains from remanufacturing: A case study of photocopier remanufacturing at Fuji Xerox Australia. J. Clean. Prod. 9, 75-81.

Khumboon, R., Kara, S., Manmek, S., Kayis, B., 2009. Environmental Impacts of Rental Service with Reconditioning - A Case Study, in: 1st CIRP Industrial Product-Service Systems (IPS2) Conference.

Kjaer, L., Høst-Madsen, N., Schmidt, J., McAloone, T., 2015. Application of Environmental Input-Output Analysis for Corporate and Product Environmental Footprints-Learnings from Three Cases. Sustainability 7, 11438-11461.

Kjaer, L.L., Pagoropoulos, A., Schmidt, J.H., McAloone, T.C., 2016. Challenges when evaluating Product/Service-Systems through Life Cycle Assessment. J. Clean. Prod. 20, 95-104.

Kjaer, L.L., Pigosso, D.C.A., McAloone, T.C., 2017. A guide for evaluating the environmental performance of Product/Service-Systems, 1st ed. Technical University of Denmark, Kgs Lyngby.

Kjaer, L.L., Pigosso, D.C.A., Niero, M., Bech, N.M., McAloone, T.C., 2018. Product/Service-Systems for a Circular Economy: the route to decoupling economic growth from resource consumption? J. Ind. Ecol. $0,1-14$.

Lelah, A., Mathieux, F., Brissaud, D., 2011. Contributions to eco-design of machine-to-machine product service systems: the example of waste glass collection. J. Clean. Prod. 19, 1033-1044.

Lindahl, M., Sundin, E., Sakao, T., 2014. Environmental and economic benefits of Integrated Product Service Offerings quantified with real business cases. J. Clean. Prod. 64, 288-296.

Mont, O., 2004. Reducing life-cycle environmental impacts through systems of joint use. Greener Manag. Int. 63-77.

Mont, O.K., 2002. Clarifying the concept of product-service system. J. Clean. Prod. 10, 237-245.

Nurhadi, L., Borén, S., Ny, H., Larsson, T., Boren, S., Ny, H., Larsson, T., 2017. Competitiveness and sustainability effects of cars and their business models in Swedish small town regions. J. Clean. Prod. 140, 333-348.

Pagoropoulos, A., Kjaer, L.L., Dong, Y., Birkved, M., Mcaloone, T.C., 2017. Economic and Environmental Impact Trade-Offs Related to In-Water Hull Cleanings of Merchant Vessels. J. Ind. Ecol. 0, 1-14.

Pereira, Á., Carballo-Penela, A., González-López, M., Vence, X., 2016. A case study of servicizing in the farming-livestock sector: Organisational change and potential environmental improvement. J. Clean. Prod. 124, 84-93.

Salazar, C., Lelah, A., Brissaud, D., 2015. Eco-designing Product Service Systems by degrading functions while maintaining user satisfaction. J. Clean. Prod. 87, 452-462.

Scheepens, A.., Vogtländer, J.., Brezet, J.C., 2016. Two life cycle assessment (LCA) based methods to analyse and design complex (regional) circular economy systems. Case: making water tourism more sustainable. J. Clean. Prod. 114, 257-268.

Tukker, A., Tischner, U., 2006. Product-services as a research field: past, present and future. Reflections from a decade of research. J. Clean. Prod. 14, 1552-1556. 
Weidema, B.P., Ekvall, T., Heijungs, R., 2009. Guidelines for application of deepened and broadened LCA, Deliverable D18 of work package 5 of the CALCAS project. 
Title: Guidelines for evaluating the environmental performance of Product/Service-Systems through Life Cycle Assessment

Highlights:

- Guidelines for LCA on PSS in six steps are presented

- Enabling comparison between PSS and traditional products

- Reducing risk of biased LCA results, rebound effects and cut-off errors

- Three types of PSS support: activity support, product support and platform support

- Three distinct cases exemplify the guidelines 
1. Goal definition

What is the purpose?

2.P55 and reference system

exploration

What to compare?

3. Comparability assessment

How to compare?

4. Process mapping

What to quantify?

5. Quantification

How to quantify?

6. Interpretation and

recommendations

What to conclude?
1.1 Study purpose and application

1.2 Study complexity

1.3 Time and resources

2.1 Scope and reference system

2.2 PSS support and substitutions

2.3 PSS potential

2.4 Definition: Systems to be analysed

3.1 System functionality and functional unit

3.2 System subdivision ("How")

3.3 Utility, value and rebound effects ("How well")

4.1 Flowchart

4.2 System boundaries

4.3 Impact categories

Goal and scope definition

5.1 Data gathering

5.2 Calculations

6.1 Result evaluation

6.2 Result communication

6.3 Recommendations (optional)
Interpretation

Impact assessment

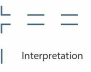

